\section{Research Square}

Preprints are preliminary reports that have not undergone peer review.

They should not be considered conclusive, used to inform clinical practice, or referenced by the media as validated information.

\title{
Assessing the evidence on the differential impact of menthol versus non- menthol cigarette use on initiation and progression to regular smoking: $A$ systematic review
}

Mimi Kim ( $\nabla$ kimm1@rirt.com )

RAIS https://orcid.org/0000-0002-1352-9670

Geoffrey M Curtin

RAIS

Research

Keywords: smoking, menthol cigarettes, systematic reviews, meta-analysis, initiation, progression to regular smoking

Posted Date: August 18th, 2020

DOI: https://doi.org/10.21203/rs.3.rs-59515/v1

License: @) (1) This work is licensed under a Creative Commons Attribution 4.0 International License. Read Full License 


\section{Abstract}

BACKGROUND: This evidence synthesis followed PRISMA guidelines to examine the Key Question: Does menthol cigarette use have a differential impact on initiation and progression to regular smoking compared to non-menthol cigarette use?

METHODS: The protocol was registered on March 22, 2016 (updated January 10, 2019; PROSPERO: CRD42019119301). Six databases were queried from inception to December 14, 2018.

RESULTS: Thirty-eight studies (19 rated as "good" and 19 rated as "fair" individual study quality) compared menthol and non-menthol cigarette smokers, and were qualitatively synthesized across four outcomes: (total adjusted studies; strength of evidence grade): age at smoking initiation (6; low); smoking initiation with menthol cigarettes (4; insufficient); switching between menthol and non-menthol cigarettes (2; insufficient); and progression to regular smoking/increased smoking over time (7; low [4 studies comparing daily versus non-daily smoking]). Generally, limited strength of evidence grades were due to issues of temporality, using current menthol status as a proxy for use at initiation. Results from two meta-analyses suggested that non-menthol smokers are more likely to report daily versus non-daily smoking; and, non-menthol smokers report younger ages at smoking initiation.

CONCLUSIONS: Based on the lack of longitudinal evidence coupled with the limited strength of evidence provided by the available studies, there is no clear, differential association between menthol (versus non-menthol) cigarette use and progression to regular smoking.

\section{Background}

To date, several literature reviews have examined the potential association between menthol cigarette use and smoking behaviors (1-4), but review methods, included studies, and overall findings and conclusions have been inconsistent. Some of the discord may reflect the complicated constructs related to smoking behaviors and the varying measurements across studies $(5,6)$.

Most recently, a systematic review of the literature to identify articles reporting on menthol versus non-menthol cigarette initiation, dependence, and cessation was performed by Villanti et al. (7). The authors reported an association between menthol cigarette smoking and increased initiation among youth, increased dependence especially among youth, and reduced cessation among non-Hispanic Whites and racial and ethnic subgroups. According to the AMSTAR 2 appraisal tool (8) for systematic review quality, there were significant methodological insufficiencies in Villanti et al.'s review, including: no PICO (population, intervention/exposure, control group, outcomes) framework for inclusion/exclusion criteria; a limited literature search strategy with only two keywords; only PubMed was searched; and no reported quality or risk of bias assessment. Instead, a subjective methodology was used to evaluate the evidence and determine associations. Thus, based on these limitations, the systematic review did not provide an accurate, credible, or comprehensive systematic synthesis of the best available evidence.

The purpose of this systematic review was to assess the potential association between menthol cigarette use and initiation/progression to regular smoking, strictly following PRISMA guidelines.

\section{Materials And Methods}

\section{Overview}

These methods and results address only one of three Key Questions (KQs) from a larger systematic review that examined the potential association between menthol cigarette use and smoking behaviors. Current results assess the KQ "Does menthol cigarette use have a differential impact on initiation and progression to regular smoking compared to non-menthol cigarette use?" Figure 1 below presents an overview for the full systematic review, with emphasis on the KQ specific to initiation/progression to regular smoking.

The protocol for this review was registered with the PROSPERO international prospective register of systematic reviews on March 22, 2016 and updated on January 10, 2019. The record is available at https://www.crd.york.ac.uk/prospero/display_record.php?RecordID=119301.

As shown in Figure 1, a total of 851 potentially relevant articles were identified. Of the 851 articles, 428 were excluded at the title/abstract level. Of the remaining 423 articles (provided in SUPPLEMENTAL SECTION 1: References Included for Full-Text review ( $\mathrm{n}=\mathbf{4 2 3}$ )), 305 were excluded at full text level (provided in SUPPLEMENTAL SECTION 2: Excluded Studies Table (studies excluded at level 2 with reason for exclusion)), resulting in 118 relevant studies eligible for inclusion (provided in SUPPLEMENTAL SECTION 3: Included Studies List $(\mathbf{n}=\mathbf{1 1 8})$ ). The weighted overall kappa for inter-rated reliability at level 2 screening was 0.96 . Thirty-eight studies (across 41 references) provided evidence on the potential association between menthol cigarette use and initiation/progression to regular smoking.

\section{Conceptual Framework}

Smoking behaviors can vary across subgroups of the population, suggesting that both individual and environmental factors influence smoking $(9,10)$. This review applied the Socio-Ecological Model created by McLeroy et al. (11) to guide consideration of the interrelationships between individuals and their micro- (social), meso- (physical), and macro- (policy) environments. Further detail on the conceptual framework is provided in SUPPLEMENTAL

\section{SECTION 4: Conceptual Framework.}

\section{Literature Search Methods}


The search strategy included sources of published peer-reviewed literature, theses and dissertations, and government and industry documents. The following online databases were searched for relevant articles published from inception to 14 December 2018: Cochrane Central Register of Controlled Trials, Cochrane Database of Systematic Reviews, Database of Abstracts of Reviews of Effects, MEDLINE, Embase and Psyclnfo. The complete search strategy is provided in SUPPLEMENTAL SECTION 5: Search Strategy.

\section{Terminology}

Evidence summaries in this review refer to "studies," "data sets," and "analyses." A study is an investigation that uses information from a data set to answer a research question. A data set may be used by multiple studies, and some studies reported analyses of more than one data set. In the summaries, the term "analyses" is used in place of "studies" wherever an included study analyzed more than one data set. Detailed descriptions of terminology that were used to organize and synthesize this review are provided in SUPPLEMENTAL SECTION 6: Terminology.

\section{Inclusion and Exclusion Criteria}

Inclusion and exclusion criteria were developed with review and input from independent tobacco research subject matter experts with expertise in systematic reviews. Reasons for exclusion of individual studies are summarized below and provided in full in SUPPLEMENTAL SECTION 7: Inclusion/Exclusion.

\section{Populations and Comparisons}

Studies that enrolled populations outside of the United States (U.S.) were excluded due to the limitations in generalizability to U.S. smoking behaviors. Studies were required to enroll smokers with an explicit use of (or stated preference for) menthol or non-menthol cigarettes. Studies were required to compare smokers of traditional menthol cigarettes with smokers of traditional non-menthol cigarettes.

\section{Outcomes and Related Psychometrics}

Included studies provided evidence on at least one of the following outcome measures: age at smoking initiation; smoking initiation with menthol cigarettes; switching between menthol and non-menthol cigarettes; and progression to regular smoking/increased smoking over time. Recognizing that not all the outcome measures are likely to be equally valid and reliable, this review examined the following Contextual Question (CQ), "Have measures used to examine initiation and progression to regular smoking been psychometrically assessed as valid and reliable?" Specific criteria were applied to assess reliability and validity across the outcome measures related to this KQ (12). Further details and psychometric scoring tables for each smokingrelated outcome measure are provided in SUPPLEMENTAL SECTION 8: Contextual Question 1.

\section{$\underline{\text { Study Designs }}$}

Since the focus of this review was the primary exposure of menthol cigarette use, included trials were reclassified depending on the eligible data. Specifically, if only baseline data from a trial were used, the study was considered cross-sectional; and, if baseline and post-baseline measurement data were used, it was considered to be a cohort study. Complete study and sample characteristics are provided in the Evidence Tables (SUPPLEMENTAL SECTION 9: Study, Dataset, and Sample Characteristics and SUPPLEMENTAL SECTION 10: Evidence Tables, Sample Characteristics (Unadjusted [Table 10-1] and Adjusted [Table 10-2])).

\section{ASSESSMENT OF INDIVIDUAL STUDY METHODOLOGY}

\section{Quality Assessment}

The quality of the studies included in this systematic review was assessed at the study level using the Downs and Black Checklist (13), which is recommended by the Cochrane Collaboration (14). Further details are provided in SUPPLEMENTAL SECTION 11: Study Quality Assessments and SUPPLEMENTAL SECTION 12: Additional Study Quality Methods.

\section{Evidence Synthesis}

The strongest evidence to assess whether menthol compared to non-menthol cigarette use has a differential impact on initiation and progression to regular smoking would be expected to be provided by longitudinal analyses that adjusted or controlled for the key confounding factors (e.g., age, race/ethnicity, and gender) by inclusion criteria, modeling, or stratification. Longitudinal analytic results would be considered the "best available" evidence and would be weighted more heavily in the strength of evidence analysis to inform the main results below. However, the evidence base was limited in longitudinal studies. Therefore, this review synthesized the highest level of available evidence according to studies that controlled for the predefined confounding factors.

\section{STRENGTH OF EVIDENCE EVALUATION}

Recognizing inherent limitations in assessing the confidence in empirical conclusions based on observational data (15-18), the Agency for Healthcare Research and Quality (AHRQ) Evidence-Based Practice Center (EPC) approach, which is based largely on the methods developed by the Grading of Recommendations Assessment, Development and Evaluation (GRADE) Working Group (19), was deemed acceptable for this review. Strength of evidence for this review was evaluated based on the four required domains: (1) study limitations, (2) directness, (3) consistency, and (4) precision. 
The overall strength of the body of evidence was assessed and graded as "high," "moderate," "low," or "insufficient" using the EPC approach. Further information on the Strength of Evidence evaluation is provided in SUPPLEMENTAL SECTION 13: Strength of Evidence.

\section{RESULTS: INITIATION/PROGRESSION TO REGULAR SMOKING}

Table 1 presents the 38 included studies according to specific outcome measures for initiation/progression to regular smoking used by each study. Overall, empirical psychometric evidence to substantiate the reliability and validity of each of the outcome measures was lacking, except for age of initiation and progression to regular use/increase smoking over time (both qualified as "Acceptable" among adult and youth populations). The remaining measures, percent who initiated to or with menthol and switching between menthol and non-menthol cigarettes, qualified as "Inconclusive" for both youth and adult populations. Further detail on the non-systematic literature synthesis for psychometric assessment is provided in SUPPLEMENTAL SECTION 8:

\section{Contextual Question 1.}

\section{Synthesis of the Best Available Evidence}

Summaries of the best available evidence (based on studies/analyses that controlled for age, race/ethnicity, and gender) are presented by outcome measure below, except when the only results for a specific outcome were unadjusted (in which case the unadjusted results represent the "best available" evidence). Results by age, race/ethnicity, and gender subgroups are presented in SUPPLEMENTAL SECTION 14: Adjusted Subgroup Analyses by Outcome; unadjusted results are presented in SUPPLEMENTAL SECTION 15: Unadjusted Results.

\section{Percent Who Initiated to or with Menthol}

Four cohort studies-three of youth and one of young adults-reported unadjusted rates of initiation to or with menthol cigarettes (20-23). Two of the studies were rated "good" quality $(21,22)$ and two were rated "fair".

Only one unadjusted study reported the percentage of participants who initiated smoking with menthol; this study was rated "fair" (23). Rath et al. (23) examined smoking patterns in the Legacy Young Adult Cohort Study (LYAC), a longitudinal sample of the young adult population in the U.S. (ages 18-34). This study's measure represents true "initiation with" menthol because participants were asked to "identify the brand they used at initiation and whether that brand was menthol or non-menthol". The authors reported that 35 percent initiated smoking with a menthol cigarette brand among the subsample of 212 participants who completed three waves of surveys and remained current cigarette smokers across all three waves.

Nonnemaker et al. $(21,22)$ analyzed data from youth who participated in the American Legacy Longitudinal Tobacco Use Reduction Study (ALLTURS) -a 3-year school-based survey of middle school and high school students, age 12 to 17 at baseline. This study assessed initiation based on the type of cigarette participants smoked at the first time point during which they were smokers and, therefore, presumes that the cigarette type that was smoked at the time of reporting was the same as the type with which participants initiated smoking. However, because there was a period of at least 1 year between baseline and the first time point during which smoking was reported, and because switching cigarette types is most likely to occur early in the smoking trajectory (Rath et al., 2015), this presumption is uncertain. As a result, this study was considered to have reported "initiation to" and not "initiation with" menthol cigarettes, and is not directly comparable with the results from Rath et al. (23).

Nonnemaker et al. (22) assessed the percentage of current smokers at year 3 who initiated to menthol cigarettes in the 2012 ALLTURS data ( $n=399)$, and found that 38.7 percent initiated smoking to menthol cigarettes (22). Among non-established smokers at wave 1 or wave 2 ( $n=638$ ), 32.6 percent initiated smoking to menthol cigarettes.

An earlier publication that presented data from ALLTURS (21) analyzed two sets of smokers - one that included youth who started smoking during wave three $(n=1,100)$ and one that excluded wave three initiators $(n=479)$. In the first set, 43.0 percent of current smokers initiated to menthol cigarettes; in the second set, 38.8 percent initiated to menthol cigarettes (statistical significance not provided). It is unclear how much overlap there was in the samples used in the 2010 and 2012 Nonnemaker publications.

DiFranza et al. (20) reported data from a longitudinal cohort study (Development and Assessment of Nicotine Dependence in Youths Study- DANDY) that enrolled youth in seventh grade at baseline from two small cities in central Massachusetts. Smoking initiation data were collected from youth who had ever "inhaled on a cigarette." A subset of 120 participants could recall whether the first cigarette they smoked was mentholated or not. Of those, 42 percent reported that the first inhaled cigarette was mentholated (statistical significance not provided). Thus, although limited, these unadjusted results suggest that fewer smokers initiate with menthol compared to non-menthol cigarettes.

\section{Age at Initiation}

Seven studies, two reporting on the same COMMIT trial and counted as one study throughout this review $(24,25)$, provided 11 adjusted analyses that assessed age at smoking initiation (24-30); sample sizes ranged from 432 to 66,145 participants. Four studies were rated "good" quality (24-26, 28, 30) and two were rated "fair" $(27,29)$.

Three studies analyzed data from the 2003 and 2006/2007 Tobacco Use Supplement to the Current Population Survey (TUS-CPS) (26, 29, 30). The smoking frequencies in the TUS-CPS, as defined by Curtin et al. (26), were as follows: (1) past-month smokers, or individuals who had smoked part or all of a cigarette on $\geq 1$ days during the month preceding participation in the survey; (2) regular smokers, or those who had smoked on $\geq 10$ days during the month prior to the survey; and, (3) daily smokers, or those who had smoked on all 30 days prior to the survey. 
Curtin et al. (26) reported that menthol smokers report statistically significant older ages of initiation compared to non-menthol cigarette smokers. Specifically, adult daily menthol smokers reported a mean age of smoking initiation of 15.7 years compared with 15.4 years for non-menthol smokers ( $p<0.001$ ); and, 15.8 years for regular menthol smokers compared to 15.6 years for non-menthol smokers $(p<0.001)$. Curtin et al. $(26)$ further reported that among past-month, regular, and daily smokers, those who smoked menthol cigarettes reported a significantly older age for smoking a whole cigarette for the first time, compared with non-menthol smokers (past-month: 12.3 versus 11.6 years, $p<0.0001$; regular: 11.9 versus 11.1 years, $p=0.004$; daily: 11.1 versus 10.3 years, $p=0.03$ ). These analyses used a continuous age variable, which may explain the difference in findings compared to earlier studies described below.

Reporting on data from the same time periods in the TUS-CPS, Fernander et al. (29) found that the odds of being a menthol smoker ("Is your usual cigarette brand menthol or non-menthol?") was only marginally associated with age of initiation (adjusted odds ratio [AOR]=1.01, 95\% Cl: 1.00 to 1.01; $p=0.0007$; age of initiation $\geq 18$ versus age of initiation $<18$ ). Lawrence et al. (30) found that smokers who began smoking regularly before the age of 15 , and those who began smoking regularly between ages 15 and 17, had the same odds of being a menthol smoker compared to smokers who started smoking regularly at age 18 or older (age of 15 : $\mathrm{AOR}=0.99,95 \% \mathrm{Cl}$ : 0.90 to 1.09 ; and, between ages 15 and 17: $\mathrm{AOR}=0.95,95 \% \mathrm{Cl}$ : 0.89 to 1.02 ).

In looking at youth in the TUS-CPS, Curtin et al. (26) reported that-among all three smoking frequencies (past-month, regular, and daily smokers) menthol smokers were significantly younger than non-menthol smokers at the start of 'fairly regular' smoking (past-month and regular: 15.1 versus 15.3 years; daily: 14.9 versus 15.1 years, all p-values $<0.01$ ). This is the only analysis of a large national survey that indicated menthol smokers reported a younger age of initiation compared to non-menthol smokers.

In similar analyses of data from the National Survey on Drug Use and Health (NSDUH; 2000-2009), Curtin et al. (26) found that past-month and regular menthol (M) smokers reported statistically significantly older ages at initiation of daily smoking compared to non-menthol (NM) smokers (M: 16.16, Standard Error [SE] $=0.07,95 \% \mathrm{Cl}: 16.01$ to 16.30 versus NM: 16.00 years, SE=0.07, $95 \%$ Cl: -0.30 to $-0.01, p=0.03$; and, M: $16.17, S E=0.08,95 \%$ Cl: 16.02 to 16.32 versus NM: 16.00 years, $S E=0.08,95 \% \mathrm{Cl}:-0.33$ to $-0.01, p=0.03$, respectively) .

According to analyses of the National Health and Nutrition Examination Survey (NHANES; 1999-2010), Curtin et al. (26) reported that past-month menthol smokers were older at the start of regular smoking, compared with non-menthol smokers (M: 15.5 years old, SE=0.20, $95 \%$ Cl: 15.1 to 15.9 versus NM: 15.4 years old, $\mathrm{SE}=0.18,95 \% \mathrm{Cl}:-0.41$ to 0.29$)$. This difference was not statistically significant.

In the reported analyses of the National Health Interview Survey (NHIS; 2005 and 2010), Curtin et al. (26) reported that past-month menthol smokers were not significantly older at the start of regular smoking, compared with non-menthol smokers (M: 15.8, SE=0.15, $95 \%$ Cl: 15.51 to 16.09 versus NM: 15.7 years, $S E=0.13,95 \%$ Cl: -0.36 to 0.14). Similarly, in an analysis of the 2005 NHIS-Cancer Control Supplement (CCS) data, Cubbin et al. (28) reported no significant differences in age at initiation between menthol and non-menthol smokers of any race/ethnicity-gender combination.

Analyses of data from three smaller survey studies, again two reporting on the same COMMIT trial $(24,25)$, examined age at initiation for menthol versus non-menthol cigarette use $(24,25,27)$. Specifically, Allen and Unger (27) found no difference in age at initiation between current menthol and non-menthol female ( $A O R=1.04,95 \% \mathrm{Cl}: 0.98$ to 1.11 ) or male ( $\mathrm{AOR}=1.03,95 \% \mathrm{Cl}: 0.97$ to 1.09$)$ smokers. The analysis by Hyland et al. $(24,25)$ found that, compared with smokers who started smoking at or younger than age 15, those who started smoking between the ages of 16 and 19 , and those who began smoking at 20 years or older, were no different in their odds of being menthol smokers (AOR=0.92, 95\% Cl: 0.82 to 1.02 , and AOR=0.89, 95\% Cl: 0.78 to 1.01 , respectively).

Overall, analyses of adult menthol smokers suggested that they have the same or an older age at initiation compared to non-menthol smokers, regardless of current smoking frequency. Although the data were limited, one analysis among youth suggested that menthol smokers were younger at initiation of "fairly regular" smoking (26); however, other studies found no difference or slightly older age at initiation of "regular" smoking in youth (24, 25, 27-30).

\section{Switching between Menthol and Non-Menthol Cigarettes}

Two prospective cohort studies reported a measure of switching cigarette type for both menthol and non-menthol smokers and adjusted for key confounders $(31,32)$, and both were rated "fair" quality.

Kasza et al. (31) examined switching between menthol and non-menthol cigarettes in a cohort of 3,118 adult smokers in the U.S. Overall switching rates were only reported as unadjusted values (see SUPPLEMENTAL SECTION 15). However, AORs for likelihood of switching were adjusted by age, race/ethnicity, and gender. Among participants who initially reported smoking menthol cigarettes, Blacks were statistically significantly less likely than Whites to switch to non-menthol cigarettes ( $\mathrm{AOR}=0.57,95 \% \mathrm{Cl}: 0.33$ to 0.99 ). However, no difference was observed in switching from menthol cigarettes to non-menthol cigarettes ( $\mathrm{AOR}=1.11,95 \% \mathrm{Cl}: 0.74$ to 1.67$)$, or for switching from non-menthol to menthol ( $\mathrm{AOR}=0.88,95 \% \mathrm{Cl}: 0.59$ to 1.32$)$ by gender. There was also no difference between Hispanics and Whites in the odds of switching to non-menthol cigarettes (AOR=1.94, 95\% Cl: 0.90 to 4.17). Among participants who initially reported smoking non-menthol cigarettes, both Blacks (AOR=11.93, 95\% Cl: 6.30 to 22.58) and Hispanics (AOR=3.16, 95\% Cl: 1.37 to 7.29 ) were statistically significantly more likely to switch to menthol cigarettes compared with Whites. Adults 25 and older were statistically significantly less likely to switch to menthol cigarettes, compared with adults age 18 to 24 (AORs ranged from 0.26 to 0.47 , respectively).

Sidney et al. (32) analyzed data from 1,688 Black smokers under the age of 40 and concluded that the odds of non-menthol cigarette smokers' switching to menthol cigarettes were statistically significantly higher than the odds of menthol smokers' switching to non-menthol (hazard ratio=4.2, $95 \% \mathrm{Cl}$ : 2.8 to 
6.4).Thus, it appears that switching between menthol and non-menthol cigarettes is not influenced by gender but may be influenced by race/ethnicity, and possibly, age.

\section{Initiation and Progression to Regular Smoking/Increase in Smoking over Time}

Seven studies presented results for initiation and progression to regular smoking or increase in smoking over time. Four of these studies were crosssectional studies comparing daily versus non-daily smoking $(26,29,30,33)$. The other three studies were longitudinal cohort studies reporting on increasing smoking over time (progression to daily smoking or becoming an established smoker) $(21,22,34)$. Of the four cross-sectional studies, three studies were rated "good" $(26,30,33)$ and one was "fair" (29); all three longitudinal studies were rated "good." Giovino et al. (33) studied data from more than 40,000 smokers at least 12 years of age in the 2008-2010 NSDUH. The investigators found no difference in the odds of being a past-30-day menthol, versus non-menthol, smoker when comparing 1 to 5 days, and 6 to 29 days, to daily smoking ( $\mathrm{OOR}=1.01,95 \% \mathrm{Cl}: 0.91$ to $1.13 ; \mathrm{p}=0.82, \mathrm{AOR}=1.02,95 \% \mathrm{Cl}$ : 0.92 to $1.12 ; p=0.73$, respectively). These findings are consistent with previously reported findings that suggested no difference between menthol and nonmenthol cigarette use among youth smokers at different stages and trajectories of smoking progression (35).

Curtin et al. (26) analyzed data from four data sets, two that included adults only (2000 to 2009 NSDUH and 1999 to 2010 NHIS), and two that provided data for both adults and youth (1999 to 2010 NHANES and 2003 and 2006/07 TUS-CPS). Among adults, the findings were mixed in the NHANES and the NSDUH data sets. When evaluating the odds of daily smoking for non-menthol smokers (i.e., menthol use is the reference group), the difference in the NSDUH analysis was statistically significant ( $A O R=1.07,95 \% \mathrm{Cl}: 1.01$ to $1.12, p=0.011)$, while the difference in the NHANES analyses was not $(A O R=1.21$, 95\% Cl: 1.00 to 1.46, $\mathrm{p}=0.05$ ). In both the NHIS and TUS-CPS, adult non-menthol smokers were different than menthol smokers to smoke daily (NHIS: AOR $=0.94,95 \% \mathrm{Cl}: 0.81$ to $1.09, p=0.39$; TUS-CPS: AOR=0.99, $95 \% \mathrm{Cl}: 0.96$ to $1.01, p=0.22$ ). Among youth, both the NHANES and the TUS-CPS analyses found that non-menthol smokers were no more likely than menthol smokers to smoke daily (NHANES: AOR=0.72, 95\% Cl: 0.49 to 1.05 , $p=0.09$; TUS-CPS: $\mathrm{AOR}=0.98,95 \% \mathrm{Cl}: 0.87$ to $1.10, \mathrm{p}=0.71)$.

Lawrence et al. (30) analyzed data from the 2003 and 2006/07 TUS-CPS, and found that daily smokers had the same odds of being a menthol smoker, compared with non-daily smokers ( $\mathrm{AOR}=1.06,95 \% \mathrm{Cl}$ : 0.94 to 1.19). These results did not change if smokers were women or men, or Hispanic. Fernander et al. (29) also analyzed data from the 2003 and 2006/07 TUS-CPS, and found similar results to Lawrence et al. (30) for likelihood of daily smokers being menthol smokers (AOR=1.06, $95 \% \mathrm{Cl}: 0.99$ to 1.14 ).

Of the three longitudinal studies, Delnevo et al. (34) found that among young adult lifetime smokers, current menthol cigarette smokers had statistically significant increasing odds of transitioning from non-daily to daily smoking over a period of 1 year, from smoking on some days to smoking daily (AOR=1.87, 95\% Cl: 1.06 to 3.30). Nonnemaker et al. (22) found that, among high school students between the ages of 12 to 17 , non-established smokers who initiated to menthol cigarettes were at higher risk of becoming established smokers over time than those who initiated to non-menthol cigarettes (adjusted relative risk ratio $=1.80,95 \% \mathrm{Cl}: 1.02$ to 3.16 ).

In another publication of the same ALLTURS high school sample, Nonnemaker et al. (21) found that youth who initiated to menthol cigarettes and remained menthol smokers were more likely to progress to daily smoking at wave 3, compared with youth who initiated to non-menthol cigarettes and remained non-menthol smokers. The authors reported analyses both including youth who participated in all three waves and excluding youth who initiated smoking at wave three. A statistically significant difference for progression to daily smoking was indicated when youth who initiated at wave 3 were included ( $\mathrm{AOR}=2.12,95 \% \mathrm{Cl}: 1.44$ to 3.12 ); however, the association was not significant with their exclusion ( $\mathrm{AOR}=1.51,95 \% \mathrm{Cl}$ : 0.67 to 3.42 ). The authors noted that youth that initiated smoking at the last of the three waves were excluded from analysis to ensure that regression model estimates examined the impact of menthol versus non-menthol cigarette use prior to and not concurrent with the smoking outcome.

Together, one analysis found that adult menthol smokers were statistically significantly less likely to be daily (vs. non-daily) smokers, compared with nonmenthol smokers (26). Two analyses found a non-significant association between menthol use and non-daily smoking (26, 33). The three overlapping analyses of the adult TUS-CPS sample all found that menthol smokers were no more likely to be daily smokers, as did analyses of the NHIS adult sample $(26,29,30)$. Of the two analyses of youth $(26)$, both found that non-menthol smokers were no more likely than menthol smokers to smoke daily. Across the three longitudinal analyses, menthol smokers were statistically significantly more likely than non-menthol smokers to increase smoking (quantity or frequency) over time, although two of the study samples included overlapping participants; however, none of the studies truly assessed menthol use at smoking initiation. While the samples included relatively new initiators, empirical data on switching cigarette type support the theory that if switching occurs, it occurs early in the smoking trajectory (23).

Therefore, these studies on initiation and progression to regular smoking provide insufficient evidence to support an association.

\section{RESULTS OF META-ANALYSIS}

Pooled data for the meta-analyses were extracted from Curtin et al. (26) reporting on analytic results that adjusted for age, race/ethnicity, and gender from four nationally representative datasets (NHANES, NSDUH, NHIS, and TUS-CPS) for both adults and youth. Details on methods and results are provided in SUPPLEMENTAL SECTION 16: Meta-Analytic Results.

Adjusted Odds of Reporting Daily Versus Non-Daily Smoking-Adults and Youth 
Adjusted odds ratios from the random effects models were calculated according to the likeness in survey items on menthol preference. Specifically, NHIS and TUS-CPS data were pooled according to "usual cigarette brand menthol or non-menthol" survey item likeness and the remaining NHANES (youth and adults) and NSDUH (adults) were pooled according to menthol use in the past 30 days. NSDUH results pooled in the meta-analysis utilized the model where the controlled dependence measures included age of first part or whole cigarette smoked.

Among the NHIS adults and the TUS-CPS full sample (including adults and youth), no difference was found between menthol and non-menthol smokers in terms of likelihood of reporting daily versus non-daily smoking. When pooling data across NHANES (youth and adults) and NSDUH (adults), reporting on two sets of results (controlling for dependence measures and demographics and controlling only for demographics), results likewise indicated no difference in the likelihood of non-menthol smokers reporting daily (versus non-daily) use compared to menthol smokers. No difference was found when controlling for dependence and demographic measures or controlling for demographics alone (with dependence measures: $\mathrm{AOR}=1.10,95 \% \mathrm{Cl}$ : 0.94 to 1.28, $\mathrm{p}$-value $=0.24, \mathrm{I}^{2}=24 \%$; without dependence measures: $\mathrm{AOR}=1.05,95 \% \mathrm{Cl}$ : 0.88 to $1.25, \mathrm{p}$-value $=0.60, \mathrm{I}^{2}=66 \%$ ).

In an effort to improve heterogeneity, the NHANES youth sample was excluded and homogeneity increased from an $\mathrm{I}^{2}$ of $24 \%$ to $0 \%$ and from $66 \%$ to $36 \%$. Specifically, when controlling for dependence and demographics, non-menthol smokers had a statistically significant and increased likelihood of reporting daily (versus non-daily) smoking compared to menthol smokers ( $\mathrm{OOR}=1.08,95 \% \mathrm{Cl}$ : 1.02 to 1.14 , $\mathrm{p}$-value $=0.006, \mathrm{I}^{2}=0 \%$ ). No difference was found between menthol and non-menthol smokers in terms of likelihood of reporting daily versus non-daily smoking when controlling for demographics alone (AOR=1.10, $95 \%$ Cl: 1.00 to 1.21 , p-value $\left.=0.06, \mathrm{I}^{2}=36 \%\right)$.

\section{Unadjusted Mean Age of Initiation-Adults and Youth}

Data to examine the mean age of initiation for non-menthol versus menthol smokers were pooled first, according to likeness of menthol survey items, and then second, according to youth versus adult analytic samples. The latter set of analyses was further stratified by smoking status (past 30 days, regular, and daily smoking).

First, according to NHIS and TUS-CPS adult samples that provided usual brand preference (non-menthol versus menthol), non-menthol smokers had a significantly younger mean age at initiation (mean difference [MD]: $0.43,95 \% \mathrm{Cl}: 0.40$ to 0.47 ; $\mathrm{p}$-value<0.00001; $\left.\right|^{2}=0 \%$ ). Similarly, among the NHANES youth, NHANES adult, and the NSDUH adult, again, pooled results suggested a significantly younger mean age for non-menthol, compared to menthol, smokers (MD: $0.59,95 \% \mathrm{Cl}$ : 0.56 to $0.62 ; \mathrm{p}$-value $\left.<0.00001 ; \mathrm{I}^{2}=0 \%\right)$.

Additionally, when pooling data according to the shared survey item asking when the respondent started "to smoke fairly regularly" across past 30 day, regular, and daily adult smokers from NHANES, NHIS, and TUS-CPS datasets, all meta-analytic results indicated a significant and younger mean age for non-menthol, compared to menthol, smokers (Past 30 day: MD: $0.43,95 \% \mathrm{Cl}: 0.40$ to $0.47, \mathrm{p}$-value<0.00001, $\mathrm{I}^{2}=0 \%$; Regular: MD: $0.43,95 \% \mathrm{Cl}$ : 0.40 to 0.47 , p-value $<0.00001, \mathrm{I}^{2}=0 \%$; and Daily: MD: $0.43,95 \% \mathrm{Cl}: 0.40$ to 0.47 , p-value $<0.00001, \mathrm{l}^{2}=0 \%$ ). When pooling additional data from the TUS-CPS with the preceding adult data, no difference in age was detected and the heterogeneity was high $\left(\mathrm{I}^{2}=98 \%\right)$.

According to the shared survey item asking when the respondent "smoked part" or "a whole cigarette" for the first time, data were pooled from the NHANES youth and NSDUH adult samples. Meta-analytic results found no difference among non-menthol and menthol regular smokers according to these two data sources $(\mathrm{p}=0.59)$. However, non-menthol smokers were found to be significantly younger at initiation, according to mean age, compared to menthol smokers, among past 30 day and daily smokers (Past 30 day: MD: 0.59, 95\% Cl: 0.56 to 0.62, p-value<0.00001, $\mathrm{I}^{2}=0 \%$; and Daily: MD: 0.53, 95\% Cl: 0.41 to 0.65 , p-value $\left.<0.00001, I^{2}=0 \%\right)$.

\section{SENSITIVITY ANALYSES-Results Adjusted for Meso-and Macro-level Factors}

Three sensitivity analyses were planned in order to test whether the results differed after more stringent inclusion and exclusion criteria were applied. Three studies were included in the sensitivity analyses by adjusting for meso- (sociocultural and physical) and macro-level (policies, government, and industry) variables in addition to age, race/ethnicity, and gender $(24,29,30)$. The sensitivity analysis of these studies yielded no difference. Details are provided in SUPPLEMENTAL SECTION 17: Sensitivity Analyses (Adjusted Results).

\section{STRENGTH OF EVIDENCE}

As presented in TABLE 2 below, the overall strength of evidence across outcomes for an association between menthol cigarette use and initiation and progression to regular smoking was graded as "low" based on several deficiencies in the "best available" body of evidence, especially indirectness and inconsistency. Most measures were "indirect" and at risk of measurement error because of the use of a surrogate measure for menthol cigarette use at initiation. Most included studies used current cigarette type as a surrogate measure for type at initiation, assuming that participants did not switch cigarette types during the period between initiation and data collection (which was decades in some studies). The only "direct" evidence was from the single study that reported "initiation with" (versus "initiation to") menthol (23).

\section{Limitations}

This systematic review was conducted according to established methodological standards and with inherent limitations. For example, the variation in the definitions of several outcome measures made it challenging to summarize results, which limited the authors' ability to draw definitive conclusions. 
Most of the smoking behavior data were self-reported. However, any impact of self-reported data in this review is expected to be minimal.

The Downs and Black checklist has some limitations when applied across a variety of study designs. Furthermore, a study's quality score on the Downs and Black checklist may reflect the quality of reporting rather than the quality of the study itself.

Finally, the conclusions in this review are based on studies conducted in the U.S. and may not be generalizable to other countries due to the potential impact of important influences, such as cultural norms, smoking policies, and taxes on smoking behaviors outside of the U.S.

\section{Discussion And Conclusions}

Overall, direct information from longitudinal cohort studies on smoking initiation with menthol cigarettes and progression to regular or daily smoking is lacking, and consequently, there is currently insufficient evidence to support an association between menthol cigarette use and smoking trajectories.

This qualitative synthesis examined literature that compared menthol to non-menthol smokers according to age at smoking initiation; smoking initiation with menthol cigarettes; switching between menthol and non-menthol cigarettes; and progression to regular smoking/increased smoking over time.

Three studies examined progression to regular smoking in youth and young adult populations $(21,22,34)$. However, none of the studies truly assessed menthol use at smoking initiation. While the samples included relatively new initiators, empirical data on switching cigarette type support the theory that if switching occurs, it occurs early in the smoking trajectory (23). Therefore, studies on progression to regular smoking suffered from the same issues of temporality as the studies of age at smoking initiation and provide insufficient evidence to support an association.

Age at initiation was one of two measures of initiation/progression to regular smoking rated with "acceptable" reliability and validity according to the psychometric evidence; however, the body of evidence on age at initiation was limited because the majority of studies measured initiation to menthol as a proxy for menthol status at initiation.

To provide a higher level of evidence, data were appropriately pooled for meta-analyses. According to meta-analytic results, non-menthol smokers were found to be significantly younger at initiation. Understanding the known issues of temporality in the evidence base, the meta-analyses informed on the outcomes of age at initiation and daily versus non-daily smoking with a higher level of evidence according to pooled results. Specifically, though the majority of cross-sectional studies evaluating menthol use and daily cigarette smoking reported no significant associations, results of a meta-analysis from government survey data (26) suggested non-menthol smokers have a higher odds of reporting daily (versus non-daily) smoking compared to menthol smokers.

In conclusion, the body of available evidence suggests non-menthol users may initiate smoking at a younger age than menthol smokers. Further, metaanalytic results suggest non-menthol smokers to be more likely to report daily, versus non-daily, smoking. However, the overall strength of evidence is insufficient to draw clear and confident conclusions about the relationship between menthol (versus non-menthol) cigarette use and progression to regular smoking.

\section{Declarations}

AUTHORS' CONTRIBUTIONS: M.K. and G.M. co-lead the conceptualization of this review and served as subject matter experts throughout the review process. M.K. led the preparation and finalization of the manuscript. G.C. served as the second author for all aspects of the manuscript preparation process including critically revising the manuscript and reviewing accuracy of all technical details. The corresponding author attests that the listed authors meet authorship criteria and that no others meeting the criteria have been omitted.

FUNDING: All study activities were executed by providers external to RAI Services Company (Venebio and Thera-Business). These providers were financially compensated for services according to contractual terms with RAI Services Company. RAI Services Company is a wholly owned subsidiary of Reynolds American Inc., whose operating companies manufacture and market tobacco products. Reynolds American Inc. was acquired by British American Tobacco in July 2017. Both Drs. Kim and Curtin serve as full-time employees of RAl Services Company.

COMPETING INTERESTS: Both Drs. Kim and Curtin serve as full-time employees of RAI Services Company, a wholly owned subsidiary of Reynolds American Inc., a manufacturer and marketer of tobacco products.

ETHICS STATEMENT: Ethical approval for this study was not required.

CONSENT FOR PUBLICATION: Not required for this publication as no individual or identifiable information is considered.

AVAILABLITY OF DATA AND MATERIALS: All data and materials considered in this review are publicly available.

ACKNOWLEDGEMENTS: The authors would like to acknowledge the Venebio Group, LLC (Richmond, VA) for providing their systematic review expertise to execute the original synthesis of the evidence base and all study activities across all levels of the review process. The authors also acknowledge TheraBusiness (Ontario CANADA) for providing their systematic review expertise to all study activities across all levels of the updated review process.

\section{Abbreviations}




\begin{tabular}{|c|c|}
\hline Abbreviation & Definition \\
\hline ALLTURS & American Legacy Longitudinal Tobacco Use Reduction Study \\
\hline AOR & adjusted odds ratio \\
\hline BRFSS & Behavioral Risk Factor Surveillance System \\
\hline CARDIA & Coronary Artery Risk Development in Young Adults \\
\hline $\mathrm{Cl}$ & confidence interval \\
\hline COMMIT & Community Intervention Trial for Smoking Cessation \\
\hline CPD & cigarettes per day \\
\hline CQ & Contextual Question \\
\hline DANDY & Development and Assessment of Nicotine Dependence in Youths Study \\
\hline EPC & Evidence-Based Practice Center \\
\hline GRADE & Grading of Recommendations Assessment, Development and Evaluation \\
\hline $\mathrm{HR}$ & hazard ratio \\
\hline ITC-4 & International Tobacco Control Four Country Survey \\
\hline KIS & Kick it at Swope \\
\hline KQ & Key Question \\
\hline LYAC & Legacy Young Adult Cohort Study \\
\hline M & Menthol \\
\hline NA & Not Applicable \\
\hline NHANES & National Health and Nutrition Examination Survey \\
\hline NHIS & National Health Interview Survey \\
\hline NHIS-CCS & National Health Interview Survey Cancer Control Supplement \\
\hline NM & non-menthol \\
\hline NSDUH & National Survey on Drug Use and Health \\
\hline PA & prolonged abstinence \\
\hline PICO & population, intervention/exposure, control group, outcomes \\
\hline POR & prevalence odds ratio \\
\hline PPA & point (or period) prevalence abstinence \\
\hline PR & prevalence ratio \\
\hline SE & standard error \\
\hline SOE & Strength of Evidence \\
\hline TUS-CPS & The Tobacco Use Supplement to the Current Population Survey \\
\hline U.S. & United States \\
\hline WSHS & Wisconsin Smokers Health Study \\
\hline $\mathrm{Yr}$ & year \\
\hline
\end{tabular}

\section{References}

1. Non-Voting Industry Representatives of the Tobacco Products Scientific Advisory Committee. Heck JD, Hamm LA, Lauterbach JH. The Industry Menthol Report. Menthol Cigarettes: No Disproportionate Impact on Public Health. 2011. Contract No.: 24 October.

2. Tobacco Products Scientific Advisory Committee. Menthol Report and Recommendation 2011 [Available from: http://www.fda.gov/downloads/AdvisoryCommittees/CommitteesMeetingMaterials/TobaccoProductsScientificAdvisoryCommittee/UCM269697.pdf.

3. U.S. Food and Drug Administration. Preliminary Scientific Evaluation of the Possible Public Health Effects of Menthol Versus Nonmenthol Cigarettes 2013 [Available from: http://www.fda.gov/downloads/ScienceResearch/SpecialTopics/PeerReviewofScientificlnformationandAssessments/UCM361598.pdf. 
4. U.S. Food and Drug Administration. Reference Addendum: Preliminary Scientific Evaluation of the Possible Public Health Effects of Menthol versus Non-menthol Cigarettes 2015 [Available from:

http://www.fda.gov/downloads/ScienceResearch/SpecialTopics/PeerReviewofScientificlnformationandAssessments/UCM362600.pdf.

5. Stanton CA, Papandonatos G, Lloyd-Richardson EE, Niaura R. Consistency of self-reported smoking over a 6-year interval from adolescence to young adulthood. Addiction. 2007;102(11):1831-9.

6. Soulakova JN, Hartman AM, Liu B, Willis GB, Augustine S. Reliability of adult self-reported smoking history: data from the tobacco use supplement to the current population survey 2002-2003 cohort. Nicotine Tob Res. 2012;14(8):952-60.

7. Villanti AC, Collins LK, Niaura RS, Gagosian SY, Abrams DB. Menthol cigarettes and the public health standard: a systematic review. BMC Public Health. 2017;17(1):983.

8. Shea BJ, Reeves BC, Wells G, Thuku M, Hamel C, Moran J, et al. AMSTAR 2: a critical appraisal tool for systematic reviews that include randomised or non-randomised studies of healthcare interventions, or both. BMJ. 2017;358:j4008.

9. Kandel DB, Kiros G-E, Schaffran C, Hu M-C. Racial/Ethnic Differences in Cigarette Smoking Initiation and Progression to Daily Smoking: A Multilevel Analysis. Am J Public Health. 2004;94(1):128-35.

10. Yi Z, Mayorga ME, Hassmiller Lich K, Pearson JL. Changes in cigarette smoking initiation, cessation, and relapse among U.S. adults: a comparison of two longitudinal samples. Tobacco Induced Diseases. 2017;15:17.

11. McLeroy KR, Bibeau D, Steckler A, Glanz K. An ecological perspective on health promotion programs. Health Educ Q. 1988;15(4):351-77.

12. Green LW, Glasgow RE. Evaluating the relevance, generalization, and applicability of research: issues in external validation and translation methodology. Eval Health Prof. 2006;29(1):126-53.

13. Downs SH, Black N. The feasibility of creating a checklist for the assessment of the methodological quality both of randomised and non-randomised studies of health care interventions. J Epidemiol Community Health. 1998;52(6):377-84.

14. Higgins JPT, Altman DG, Sterne JAC. Section 13.5. Assessing risk of bias in non-randomized studies. In: Higgins JPT, Green S, editors. Cochrane Handbook for Systematic Reviews of Interventions. Version 5.1.0: The Cochrane Collaboration; 2011.

15. Wells GA, Shea B, Higgins JP, Sterne J, Tugwell P, Reeves BC. Checklists of methodological issues for review authors to consider when including nonrandomized studies in systematic reviews. Res Synth Methods. 2013;4(1):63-77.

16. Schunemann HJ, Tugwell P, Reeves BC, AkI EA, Santesso N, Spencer FA, et al. Non-randomized studies as a source of complementary, sequential or replacement evidence for randomized controlled trials in systematic reviews on the effects of interventions. Res Synth Methods. 2013;4(1):49-62.

17. Norris SL, Moher D, Reeves BC, Shea B, Loke Y, Garner S, et al. Issues relating to selective reporting when including non-randomized studies in systematic reviews on the effects of healthcare interventions. Res Synth Methods. 2013;4(1):36-47.

18. Higgins JP, Ramsay C, Reeves BC, Deeks JJ, Shea B, Valentine JC, et al. Issues relating to study design and risk of bias when including nonrandomized studies in systematic reviews on the effects of interventions. Res Synth Methods. 2013;4(1):12-25.

19. Group GW. Grading quality of evidence and strength of recommendations. BMJ: British Medical Journal. 2004;328(7454):1490-.

20. DiFranza JR, Savageau JA, Fletcher K, Ockene JK, Rigotti NA, McNeill AD, et al. Recollections and repercussions of the first inhaled cigarette. Addict Behav. 2004;29(2):261-72.

21. Nonnemaker J, Hersey J, Homsi G, Busey A. Menthol cigarettes and youth smoking updake. RTI International; 2010.

22. Nonnemaker J, Hersey J, Homsi G, Busey A, Allen J, Vallone D. Initiation with menthol cigarettes and youth smoking uptake. Addiction. 2012;108(1):171-8.

23. Rath JM, Villanti AC, Williams VF, Richardson A, Pearson JL, Vallone DM. Patterns of Longitudinal Transitions in Menthol Use Among US Young Adult Smokers. Nicotine Tob Res. 2015;17(7):839-46.

24. Hyland A, Garten S, Giovino GA, Cummings KM. Mentholated cigarettes and smoking cessation: Findings from COMMIT. Tob Control. 2002;11:135-9.

25. Hyland A, Rivard C. Analysis of mentholated cigarettes using the COMMIT data - summary. Department of Health Behavior, Roswell Park Cancer Institute; 2010.

26. Curtin GM, Sulsky SI, Van Landingham C, Marano K, Graves MJ, Ogden MW, et al. Measures of initiation and progression to increased smoking among current menthol compared to non-menthol cigarette smokers based on data from four U.S. government surveys. Regul Toxicol Pharmacol. 2014;70(2):446-56.

27. Allen B Jr, Unger JB. Sociocultural correlates of menthol cigarette smoking among adult African Americans in Los Angeles. Nicotine Tob Res. 2007;9(4):447-51.

28. Cubbin C, Soobader MJ, LeClere FB. The intersection of gender and race/ethnicity in smoking behaviors among menthol and non-menthol smokers in the United States. Addiction. 2010;105(Suppl 1):32-8.

29. Fernander A, Rayens MK, Zhang M, Adkins S. Are age of smoking initiation and purchasing patterns associated with menthol smoking? Addiction. 2010;105(Suppl 1):39-45.

30. Lawrence D, Rose A, Fagan P, Moolchan ET, Gibson JT, Backinger CL. National patterns and correlates of mentholated cigarette use in the United States. Addiction. 2010;105(Suppl 1):13-31.

31. Kasza KA, Hyland AJ, Bansal-Travers M, Vogl LM, Chen J, Evans SE, et al. Switching between menthol and nonmenthol cigarettes: findings from the U.S. Cohort of the International Tobacco Control Four Country Survey. Nicotine Tob Res. 2014;16(9):1255-65. 
32. Sidney S, Tekawa IS, Friedman GD. Mentholated cigarette use among multiphasic examinees, 1979-86. Am J Public Health. 1989;79:1415-6.

33. Giovino GA, Villanti AC, Mowery PD, Sevilimedu V, Niaura RS, Vallone DM, et al. Differential trends in cigarette smoking in the USA: is menthol slowing progress? Tob Control. 2015;24(1):28-37.

34. Delnevo CD, Villanti AC, Wackowski OA, Gundersen DA, Giovenco DP. The influence of menthol, e-cigarettes and other tobacco products on young adults' self-reported changes in past year smoking. Tob Control. 2015.

35. Caraballo RS, Asman K. Epidemiology of menthol cigarette use in the United States. Tob Induc Dis. 2011;9(Suppl 1):1.

36. Alexander LA, Crawford T, Mendiondo MS. Occupational status, work-site cessation programs and policies and menthol smoking on quitting behaviors of US smokers. Addiction. 2010;105(Suppl 1):95-104.

37. Benowitz NL, Dains KM, Dempsey D, Havel C, Wilson M, Jacob P. 3rd. Urine menthol as a biomarker of mentholated cigarette smoking. Cancer Epidemiol Biomarkers Prev. 2010;19(12):3013-9.

38. Curtin GM, Sulsky SI, Van Landingham C, Marano KM, Graves MJ, Ogden MW, et al. Patterns of menthol cigarette use among current smokers, overall and within demographic strata, based on data from four U.S. government surveys. Regul Toxicol Pharmacol. 2014;70(1):189-96.

39. DiFranza JR, Savageau JA, Fletcher K, Ockene JK, Rigotti NA, McNeill AD, et al. Measuring the loss of autonomy over nicotine use in adolescents: the DANDY (Development and Assessment of Nicotine Dependence in Youths) study. Arch Pediatr Adolesc Med. 2002;156(4):397-403.

40. Fagan P, Moolchan ET, Hart A Jr, Rose A, Lawrence D, Shavers VL, et al. Nicotine dependence and quitting behaviors among menthol and non-menthol smokers with similar consumptive patterns. Addiction. 2010;105(Suppl 1):55-74.

41. Fagan P, Pohkrel P, Herzog T, Pagano I, Vallone D, Trinidad DR, et al. Comparisons of three nicotine dependence scales in a multiethnic sample of young adult menthol and non-menthol smokers. Drug Alcohol Depend. 2015;149:203-11.

42. Faseru B, Choi WS, Krebill R, Mayo MS, Nollen NL, Okuyemi KS, et al. Factors associated with smoking menthol cigarettes among treatment-seeking African American light smokers. Addict Behav. 2011;36(12):1321-4.

43. Faseru B, Nollen NL, Mayo MS, Krebill R, Choi WS, Benowitz NL, et al. Predictors of cessation in African American light smokers enrolled in a bupropion clinical trial. Addict Behav. 2013;38(3):1796-803.

44. Gandhi KK, Foulds J, Steinberg MB, Lu SE, Williams JM. Lower quit rates among African American and Latino menthol cigarette smokers at a tobacco treatment clinic. Int J Clin Pract. 2009;63(3):360-7.

45. Hersey JC, Ng SW, Nonnemaker JM, Mowery P, Thomas KY, Vilsaint MC, et al. Are menthol cigarettes a starter product for youth? Nicotine Tob Res. 2006;8(3):403-13.

46. Hersey JC, Nonnemaker J, Homsi G, Allen J. Menthol cigarettes, saliva cotinine, and nicotine dependence in adolescents. 2010.

47. Jain RB. Trends in serum cotinine concentrations among daily cigarette smokers: data from NHANES 1999-2010. Sci Total Environ. 2014;472:72-7.

48. Jones MR, Apelberg BJ, Tellez-Plaza M, Samet JM, Navas-Acien A. Menthol cigarettes, race/ethnicity, and biomarkers of tobacco use in U.S. adults: the 1999-2010 National Health and Nutrition Examination Survey (NHANES). Cancer Epidemiol Biomarkers Prev. 2013;22(2):224-32.

49. Okuyemi KS, Ebersole-Robinson M, Nazir N, Ahluwalia JS. African-American menthol and nonmenthol smokers: Differences in smoking and cessation experiences. J Natl Med Assoc. 2004;96(9):1208-11.

50. Okuyemi KS, Faseru B, Sanderson Cox L, Bronars CA, Ahluwalia JS. Relationship between menthol cigarettes and smoking cessation among African American light smokers. Addiction. 2007;102(12):1979-86.

51. Park J-Y. Tobacco use behaviors among vulnerable populations. Dissertation Abstracts International: Section B: The Sciences and Engineering. 2017;77(12-B(E)):No-Specified.

52. Pletcher MJ, Hulley BJ, Houston T, Kiefe Cl, Benowitz N, Sidney S. Menthol cigarettes, smoking cessation, atherosclerosis, and pulmonary function. Arch Intern Med. 2006;166:1915-22.

53. Resnicow K, Zhou Y, Scheuermann TS, Nollen NL, Ahluwalia JS. Unplanned quitting in a triethnic sample of U.S. smokers. Nicotine Tob Res. 2014;16(6):759-65.

54. Rosenbloom J, Rees VW, Reid K, Wong J, Kinnunen T. A cross-sectional study on tobacco use and dependence among women: Does menthol matter? Tob Induc Dis. 2012;10(19):1-6.

55. Smith SS, Fiore MC, Baker TB. Smoking cessation in smokers who smoke menthol and non-menthol cigarettes. Addiction. 2014;109(12):2107-17.

56. Stahre M, Okuyemi KS, Joseph AM, Fu SS. Racial/ethnic differences in menthol cigarette smoking, population quit ratios and utilization of evidencebased tobacco cessation treatments. Addiction. 2010;105(Suppl 1):75-83.

57. Sulsky SI, Fuller WG, Van Landingham C, Ogden MW, Swauger JE, Curtin GM. Evaluating the association between menthol cigarette use and the likelihood of being a former versus current smoker. Regul Toxicol Pharmacol. 2014;70(1):231-41.

58. Villanti AC, Giovino GA, Barker DC, Mowery P, Sevilimedu V, Abrams DB. Menthol brand switching among adolescents and young adults in the national youth smoking cessation survey. Am J Public Health. 2012;102(7):1310-12.

59. Muilenburg JL, Legge JS. Jr. African American adolescents and menthol cigarettes: smoking behavior among secondary school students. J Adolesc Health. 2008;43(6):570-5.

60. Oncken C, Feinn R, Covault J, Duffy V, Dornelas E, Kranzler HR, et al. Genetic Vulnerability to Menthol Cigarette Preference in Women. Nicotine Tob Res. 2015;17(12):1416-20. 
61. Fagan P, Pokhrel P, Herzog TA, Pagano IS, Franke AA, Clanton MS, et al. Nicotine Metabolism in Young Adult Daily Menthol and Nonmenthol Smokers. Nicotine Tob Res. 2016;18(4):437-46.

62. Park SJ, Foreman MG, Demeo DL, Bhatt SP, Hansel NN, Wise RA, et al. Menthol cigarette smoking in the COPDGene cohort: relationship with COPD, comorbidities and CT metrics. Respirology. 2015;20(1):108-14.

\section{Tables}

Table 1: Outcome Measures: Initiation and Progression to Regular Smoking

Measure
OVERALL RESULTS
$\begin{aligned} & \text { A total of } 38 \text { studies evaluated the potential association between menthol versus non-menthol cigarette use and initiation/progression to regular } \\ & \text { smoking. }\end{aligned}$

\section{Studies}

Of these, adjusted results are presented from 13 studies.

Unadjusted results are presented from 36 studies.

$(21-26,28-33,35-61)$

Both adjusted and unadjusted results presented from 11 of these studies.

Two of the studies, one published and one unpublished, report the same COMMIT data and are therefore counted as one study.

Two other studies report data from the same Hawaiian sample and therefore are counted as one study.

Two studies report data from the same randomized, placebo-controlled trial of bupropion, in combination with health education counseling, for smoking cessation among African American light smokers (Kick it at Swope III).

\section{Age at initiation}

Age smoked first cigarette

$(20,26,42,49,52,55$ $60,62)$

Age first used tobacco

Age started smoking/age first smoked

Age started smoking fairly regularly

Age started smoking regularly

Age started smoking daily

Age started smoking at current level

\section{Percent who initiated to or with $\mathrm{M}$}

Percent of smokers whose first brand of cigarettes used was $\mathrm{M}$ (initiated with $\mathrm{M}$ )

Percent of current $\mathrm{M}$ smokers whose first brand of cigarettes used was $M$ (initiated to $M$ )

\section{Switching between M/NM cigarettes}

Of current M smokers, \% who switched from NM to M

Of current NM smokers, \% who switched from M to NM

\section{Progression to regular smoking/increase in smoking over time}

Escalating to established smoking after initiating with $\mathrm{M}$ cigarettes

Change over past year from smoking not at all or some days to daily

CPD stratified by smoking $<1$ yr versus $>1 \mathrm{yr}$

Current smokers who initiated smoking within past two years, stratified by smoking days per month and CPD (stages and/or trajectories of smoking)

Daily versus non-daily smoking among $\mathrm{M}$ and NM cigarette smokers 


\begin{tabular}{|c|c|c|c|c|c|c|c|}
\hline Measure & $\begin{array}{l}\text { Study } \\
\text { limitations }\end{array}$ & Directness & Consistency & Precision & SOE & $\begin{array}{l}\text { CQ } \\
\text { assessment }\end{array}$ & $\begin{array}{l}\text { Overall SOE Across Measures - Adjusted } \\
\text { and Unadjusted }\end{array}$ \\
\hline \multicolumn{8}{|l|}{ Age at initiation } \\
\hline ADJUSTED & Low & Indirect & Inconsistent & Precise & Low & Acceptable & \multirow[t]{2}{*}{ Adjusted Measures: LOW } \\
\hline UNADJUSTED & Medium & Indirect & Inconsistent & Imprecise & Insufficient & Acceptable & \\
\hline \multicolumn{7}{|l|}{ Initiation type } & \multirow[t]{10}{*}{ Unadjusted Measures: INSUFFICIENT } \\
\hline ADJUSTED & NA & NA & NA & NA & Insufficient & Inconclusive & \\
\hline UNADJUSTED & Medium & Mixed* & Consistent & Unknown & Insufficient & Inconclusive & \\
\hline \multicolumn{7}{|l|}{ Switching } & \\
\hline ADJUSTED & Medium & Indirect & Inconsistent & Imprecise & Insufficient & Inconclusive & \\
\hline UNADJUSTED & Low & Indirect & Inconsistent & Unclear & Insufficient & Inconclusive & \\
\hline \multicolumn{7}{|l|}{ Progression } & \\
\hline ADJUSTED & Low & Indirect & Consistent & Precise & Low & Acceptable & \\
\hline UNADJUSTED & Low & Indirect & Inconsistent & Imprecise & Insufficient & Acceptable & \\
\hline \multicolumn{7}{|c|}{ * Mixed $=1$ direct, 2 indirect } & \\
\hline $\mathrm{CQ}=$ contextu & uestion; NA & applicable; & $E=$ strength & f evidence & & & \\
\hline
\end{tabular}

Overall Strength of Evidence Assessment

\begin{tabular}{|c|c|c|c|}
\hline Measure & CQ Assessment & Measure SOE & $\begin{array}{l}\text { Outcome } \\
\text { SOE }\end{array}$ \\
\hline \multicolumn{4}{|c|}{ Adjusted Analyses } \\
\hline Initiation age & Acceptable & Low & \multirow[t]{4}{*}{ Low } \\
\hline Initiation type & Inconclusive & Insufficient & \\
\hline Switching & Inconclusive & Insufficient & \\
\hline Progression & Acceptable & Low & \\
\hline \multicolumn{4}{|c|}{ Unadjusted Analyses } \\
\hline Initiation age & Acceptable & Insufficient & \multirow[t]{4}{*}{ Insufficient } \\
\hline Initiation type & Inconclusive & Insufficient & \\
\hline Switching & Inconclusive & Insufficient & \\
\hline Progression & Acceptable & Insufficient & \\
\hline $\mathrm{CQ}=$ contextua & Iestion; NA = not a & cable; SOE = str & th of evidenc \\
\hline
\end{tabular}

\section{Figures}




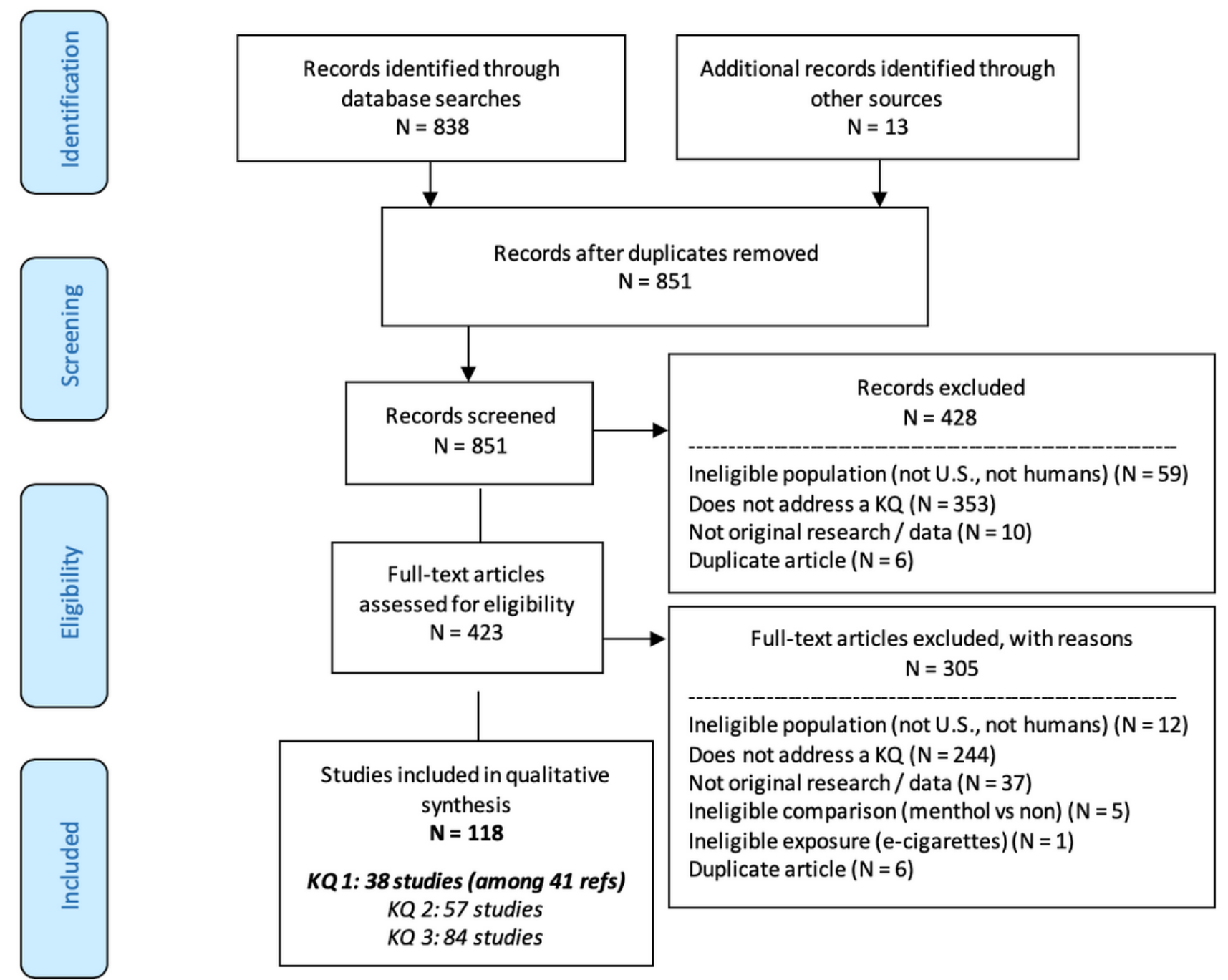

Figure 1

Literature Search Overview

\section{Supplementary Files}

This is a list of supplementary files associated with this preprint. Click to download.

- KQ1mentholSysRevSUPPSFINALAUG132020.docx

- ISSMPRISMAChecklist.pdf 